\title{
Physicalism and the nature of phenomenal concepts
}

\author{
Fisicalismo e a natureza dos \\ conceitos fenomenais
}

\begin{abstract}
André Joffily Abath
Doutor em Filosofia pela Universidade de Sheffield, professor adjunto I na Universidade Federal da Paraíba (UFPB), João Pessoa, PB - Brasil, e-mail: andreabath@gmail.com
\end{abstract}

\begin{abstract}
In recent years, a number of authors have tried to respond to Frank Jackson's so-called "Knowledge Argument" against physicalism by appealing to phenomenal concepts, that is, concepts under which fall the phenomenal aspect of our experiences, or, to put it in different terms, concepts under which fall the sensations attached to our experiences. However, there is no agreement in the literature regarding the nature of phenomenal concepts. For some, these concepts are recognitional in nature. Others take them as being demonstrative in nature. In this paper, I will argue that physicalists should not take phenomenal concepts as being either recognitional or demonstrative in nature, for if they do they will not be able to respond to Jackson's Knowledge Argument.
\end{abstract}

Keywords: Phenomenal concepts. Physicalism. Recognitional concepts. Demonstrative concepts. Attention. 


\section{Resumo}

Recentemente, um número considerável de autores buscaram responder ao chamado "Argumento do Conhecimento" de Frank Jackson contra o fisicalismo por meio de um apelo a conceitos fenomenais, tomados como sendo aqueles sob os quais caem os aspectos fenomenais de nossas experiências, ou, posto de outra forma, sob os quais caem as sensações vinculadas a nossas experiências. Contudo, não há acordo na literatura acerca da natureza dos conceitos fenomenais. Para alguns, tais conceitos são de natureza recognicional. Para outros, eles são de natureza demonstrativa. Neste artigo, argumentarei que os fisicalistas não devem tomar conceitos fenomenais como sendo quer recognicionais, quer demonstrativos, pois, caso o façam, serão incapazes de responder ao Argumento do Conhecimento de Jackson.

Palavras-chave: Conceitos fenomenais. Fisicalismo. Conceitos recognicionais. Conceitos demonstrativos. Atenção.

\section{Introduction}

Frank Jackson (1982, p. 130) famously argues that physicalism is false on the basis of the following thought experiment:

Mary is a brilliant scientist who is, for whatever reason, forced to investigate the world from a black and white room via a black and white television monitor. She specializes in the neurophysiology of vision and acquires, let us suppose, all the physical information there is to obtain about what goes on when we see ripe tomatoes, or the sky, and use terms like 'red', 'blue', and so on. What will happen when Mary is released from her black and white room or is given a color television monitor? Will she learn anything or not? It seems just obvious that she will learn something about the world and our visual experience of it. But then it is inescapable that her previous knowledge was incomplete. But she had all the physical information. Ergo there is more to have than that, and Physicalism is false.

The idea here is that, if physicalism is true - that is, if, necessarily, everything is physical -, knowing all there is to know about the physical 
processes involved in colour perception should imply knowing all there is to know about colour perception. But, according to Jackson, this is false, since, in perceiving colours such as red for the first time, Mary learns something, even though she does know everything there is to know about the physical processes involved in colour perception. So, physicalism is false. This is the so-called "Knowledge Argument" (KA) against physicalism.

Physicalists have responded to the KA in different ways. But, lately, one style of response has become prominent, one that appeals to phenomenal concepts. These are the concepts under which fall the phenomenal aspect of our experiences, the sensations attached to them. Thus, the concept "red sensation" is a phenomenal concept. It is a concept under which fall the phenomenal aspect of a red-experience, the sensations we have when seeing red. So is the concept "vanilla sensation", a concept under which fall the phenomenal aspect of a vanilla-experience, the sensations we have when tasting vanilla.

How are physicalists supposed to use phenomenal concepts in order to defend themselves from the KA? Well, phenomenal concepts are supposed to be isolated from non-phenomenal concepts, in the sense that they cannot be derived from non-phenomenal concepts. Thus, possession of non-phenomenal concepts does not lead to possession of phenomenal ones. Let us now go back to Mary's case. The idea here is that Mary, despite possessing all physical information regarding colour perception, does not possess any concepts for sensations associated with the perception of colours such as red. After all, what Mary possesses are non-phenomenal concepts that capture the physical processes involved in colour perception. But possession of such concepts does not lead to possession of any phenomenal concepts related to colour perceptions or experiences. To acquire a phenomenal concept such as "red sensation", Mary needs to experience the colour red. Thus, when Mary leaves her room and perceives colours such as red for the first time, what she acquires are precisely phenomenal concepts, such as "red sensation". She can then entertain thoughts about red sensations, thoughts she could not entertain before. There is then something that Mary acquires in leaving the room.

How is this supposed to help physicalists in responding to Jackson's KA? Well, the idea is that what fall under phenomenal concepts - sensations are physical events. In fact, one can possess non-phenomenal concepts for these events. Mary, in her black and white room, possessed them. It was just that Mary, while in the room, could only bring these events under nonphenomenal concepts. Once she leaves the room and acquires new concepts phenomenal ones - for the sensations attached to colour experiences, she is 
able to bring these events under her new concepts. And all of this is perfectly compatible with physicalism.

This response to the KA is potentially powerful in that it respects the intuition that Mary does acquire something new in leaving the room (new concepts), but in rejecting Jackson's step from this fact to the falsity of physicalism.

There is then good reason to explore the response in detail. In doing so, there are questions we must face, such as: What is the nature of phenomenal concepts? People such as Loar (1990), Carruthers (2000) and Tye (2000) have taken phenomenal concepts to be recognitional concepts. Others, such as Perry (2001), have taken phenomenal concepts to be demonstrative concepts. In this paper, I will argue that, if phenomenal concepts are either recognitional or demonstrative, then we do not possess concepts for the phenomenal aspect of most colour experiences. If that is the case, physicalists would not be able to respond to the KA in the manner described above. If, on the other hand, phenomenal concepts are not taken to be either demonstrative or recognitional, then physicalists face the challenge of explaining what their nature is.

I'll proceed as follows. In section 1, I outline the position according to which phenomenal concepts are recognitional concepts. In section 2, I show that, if this is the case, we do not possess concepts for the phenomenal aspect of most colour experiences. In section 3, I outline the position according to which phenomenal concepts are demonstrative concepts. In section 4, I show that, if phenomenal concepts are demonstrative, then again we do not possess concepts for the phenomenal aspect of most colour experiences.

\section{Phenomenal concepts as recognitional concepts}

The position according to which phenomenal concepts are recognitional was first explicitly defended by Loar. He writes (1990, p. 87):

Phenomenal concepts are recognitional/imaginative concepts. Given a normal background of cognitive capacities, certain recognitional or discriminative dispositions suffice for having specific recognitional concepts, which is to say, suffice for the capacity to make judgements that depend specifically on those recognitional dispositions. Simples such judgements have the form: the object (event, situation) a is one of that 
kind, where the cognitive backing for the predicate is just a recognitional disposition, i.e., a disposition to classify objects (events, situations) together...

So, according to Loar, phenomenal concepts are of the form " $\mathrm{X}$ (a sensation, for instance) is one of that kind", where this is short for "sensation X (for instance) is of the same kind as that sensation", that sensation being one had in the past. From this we can extract a condition regarding the possession of phenomenal concepts. If such concepts have the form Loar thinks they have, then one can only possess a phenomenal concept for a sensation $\mathrm{X}$ if one if able to recognize $\mathrm{X}$, that is, if one is able to take $\mathrm{X}$ as being of the same kind as a sensation had in the past. Take the case of colour experience. Given a perception of red, and a sensation that accompanies it in a given subject, a subject will possess a concept for the sensation only if she is able to take it as being a sensation of the same kind as sensations had in the past.

Now, we often speak of having experiences of red in general, of blue in general, green, and so forth. But, as a matter of fact, what is given to us in experience is not general redness, or blueness, and so on. Rather, in experience we are presented with specific shades of red, specific shades of blue, green etc. Right now, the book in front of me is presented to me as having a specific shade of red. Since I have no expression for the shade in my vocabulary, I call it simply "red". But clearly I take the colour of the book as being different from the colour of blood, from the colour of the Chinese flag, and from the colour of my friend Julie's hair. I'm never presented in experience with redness only. I'm presented with specific shades of redness.

Clearly, different sensations are attached to experiences of different shades of red. The sensation I have when presented with Chinese flag-red is different from the sensation I have when presented with blood-red and when presented with Julie's hair-red. And the sensations are different not only because my emotional responses to the Chinese flag, to blood and to Julie are different. They differ in part only because different shades of red are presented to me. After all, when looking at two different shades of red, we are aware that they differ. And, in being so aware, the phenomenological aspect of the experiences differs. Different sensations are displayed.

Moving back to Mary's case, we should then say that, when she leaves her black and white room and perceives redness, it is not redness in 
general she is presented with, but with a specific shade of red. Maybe the shade of red of traffic lights, maybe the shade of red of someone's blood.

Is this fact a problem for physicalists? Loar doesn't think it is. After all, he seems to think we possess recognitional concepts for the sensations that accompany experiences of specific shades of red. He writes: "We have phenomenal recognitional concepts of various degrees of generality. Some are of highly determinate qualities, and others are of phenomenal determinables: crimson, dark red, red, warm-colored, colored, visual" (LOAR, 1990, p. 95).

If we had concepts for the sensations that accompany the experiences of specific shades of colour, then physicalists could still have their response to the KA. After all, Mary, in leaving her room, would be acquiring a concept for a sensation attached to an experience of a specific shade of red, a sensation that would still be taken as being a physical event. Once again, we would be able to explain what it is that Mary acquires in leaving her room, while still holding on to physicalism.

Unfortunately, things are not so simple. For there is empirical evidence suggesting that, after all, we are not able to recognize most specific shades of colour, not even for a short while. And if we do not have this recognitional capacity (or disposition), then we cannot be said to possess recognitional concepts for most specific shades of colour. In which case it seems that we would also not be able to recognize most sensations attached to experiences of specific shades of colour, and would not then possess recognitional concepts for most of these sensations. In short, if phenomenal concepts are recognitional, then we do not possess concepts for the phenomenal aspect of most of our colour experiences, since we are not able to recognize such phenomenal aspects in most cases. So, Mary, in leaving her room, would not be acquiring recognitional concepts for most of her new sensations attached to the experiences of specific shades of colour. That, of course, would be a problem for the physicalists' response to the KA, since they would no longer be able to explain what it is that Mary acquires in leaving her room as she experiences specific shades of colour.

These consequences, of course, only follow if there is indeed empirical evidence that we are not able to recognize most specific shades of colour presented to us in experience. In the next section, I present such evidence, and then consider the consequences briefly mentioned above in more detail. 


\title{
Recognition of specific shades of colour and sensations attached to them: the evidence
}

The evidence regarding our capacities of recognition of specific shades of colour comes from experiments that were run in order to test how well we remember colours. The most famous of these experiments was run by Burnham and Clark (1955, p. 166). They gave the following instructions to the subjects:

\begin{abstract}
This is a test to find out how well you remember colors. I am going to expose a color here, like this, for five seconds and ask you to look at it with the idea of remembering what it looks like so you can pick out the color which looks the most like it from a large group of colors. Then I shall spin the wheel and move the sliding panel, like this, and ask you to look away at the black surface of the cover until I say "now". At this signal, look back at the spinning wheel of colors and, using this knob, slow down the wheel, find the color which looks like the one shown you before and stop the wheel with that color showing in the circular hole.
\end{abstract}

The wheel in case had two circles: a first one with 43 colour chips of different hues in it, and a second one with 22 colour chips of different hues. In the second circle were the test chips. That is, the chips that subjects were asked to look at attentively for five seconds. In the first circle were the chips the subjects had to select as looking the most like the chip they were presented with before. So, a subject was shown a given chip, say, a reddish-yellow, for five seconds. Then the chip was taken away from her view. After five seconds, the subject was asked to choose among 43 chips on the first circle of the wheel the one which looked the most like the chip that was presented five seconds before. Since an identical chip to the one the subject had seen would always be on the first circle, if the subject succeeded in the task she would be picking out the chip seen before (an identical chip to the one seen before) among 43 others.

One hundred thirty subjects were tested for 20 different chips of colour. The highest number of correct answers was relative to chip 13, a reddishyellow. After being shown chip 13 for five seconds, and after the chip being taken away from their view for five seconds, 69 out of 130 subjects were able to pick out chip 13 among 43 others as being the one which they had been shown before (BURNHAM; CLARK 1955, p. 168). The lowest number 
of correct answers was relative to chip 37, a nearly pure green. After being shown chip 37 for five seconds, and after the chip being taken away from their view for five seconds, only 29 out of 130 subjects were able to pick out chip 37 among 43 others as being the one which they had been shown before (BURNHAM; CLARK 1955, p. 168). For most of the chips, less than half of the subjects were able to pick out the test chip after five seconds, among 43 chips.

In 2004, Epps and Kaya published the results of a similar experiment, this time dividing the subjects (40 of them) in two groups, half with prior colour training (students majoring in design), and half with no prior colour training. Subjects were asked to look at a colour chip for five seconds. Then the chip was taken away from their view. Five seconds later, subjects were asked to choose among ten chips the test chip they had seen before. All the ten chips resembled the test chip. Subjects were tested for four chips. Twenty nine out of 40 subjects were able to pick out a yellowish chip among the other ten. But for the other three chips, less than half of the subjects were able to pick out the test chip correctly. In fact, only five out of 40 subjects were able to pick out a green chip among ten other chips. Little difference was found between the recognitional abilities of subjects with prior colour training and subjects with no colour training (EPPS; KAYA, 2004, p. 20).

These results are similar to the results obtained in Burnham e Clark's (1955) experiment. Most subjects are able to recognize yellowish chips after a five second delay between the original presentation of the chip and its presentation among other chips. But for most chips this is not the case. Most subjects are unable to recognize the chip originally presented among others after a five second delay. And the task seems to be particularly difficult for green chips. For such chips, the vast majority of subjects are not able to recognize them among other chips after a five second delay.

So, this is the evidence regarding our capacity to recognize for a short while the shades of colour that are presented to us in experience. Next, I will consider the consequences of this evidence for our discussion.

\section{Consequences}

So, we now know that we are not able to recognize most shades of colour presented to us in experience, not even for a short period of time. In being presented with shades of green, subjects are not able to tell if a shade 
presented five seconds later is of the same kind as the one presented before or not. But what is the consequence of this fact for the question of whether we possess recognitional concepts for the phenomenal aspect of our colour experiences? Well, simply put, given the evidence, we do not possess recognitional concepts for most of the specific shades of colour we are presented with in perceptual experience. After all, in being presented with such shades, we do not acquire (in most cases) a capacity (or disposition) to recognize them, not even for a short while. Since having this capacity is necessary for possession of recognitional concepts, we do not possess recognitional concepts for most of the specific shades of colour we are presented with in perceptual experience. If we possess any concepts for most of the specific shades we are presented with, they cannot be recognitional.

Now, if that is the case, then Mary, in leaving her room, does not acquire recognitional concepts for most of the shades of colour she is presented with. She does not acquire a recognitional concept for the shade of green of a traffic light, or for the shade or red of her bed's sheets. After all, she is, like us, unable to recognize most shades of colour.

Being so unable, it seems clear that Mary is also unable to recognize the sensations attached to experiences of specific shades of colour. If I'm not able to recognize a given shade of red, not even for a short while after its original presentation, how can I be able to recognize the sensation attached to the experience of the shade? For instance, if, in being shown the colour of Julie's hair, I'm not able to recognize it later on, how can I be able to recognize the sensation attached to the experience of Julie's hair colour? That is, how can I be able to recognize a sensation attached to an experience if I'm not able to recognize the object of the experience? It seems clear that I cannot. Mary is no different. In being unable to recognize specific shades of red, she is unable to recognize the sensations attached to the experience of these shades.

As we have seen, if phenomenal concepts are recognitional, it is a necessary condition for their possession for a given sensation that the subject is able to recognize the sensation. In the case of colour experience, we are not able to recognize the sensations attached to most of them. So, if phenomenal concepts are recognitional, we do not possess phenomenal concepts for the sensations attached to most of our colour experiences. Thus, if phenomenal concepts are recognitional, then Mary does not possess phenomenal concepts for the sensations attached to most of her colour experiences.

This is, of course, a problem for the physicalists' response to the KA in terms of our possession of recognitional phenomenal concepts. The 
response is attractive because it attempts to explain what it is that Mary acquires in leaving her room while, at the same time, holding on to physicalism. According to the physicalists, Mary acquires phenomenal concepts in leaving her room as she is presented with shades of colour in perceptual experience. Moreover, a good number of physicalists take such concepts to be recognitional. However, if what I have said is correct, given the idea that phenomenal concepts are recognitional, Mary does not acquire phenomenal concepts for the sensations attached to most of her experiences of shades of colour. So, if physicalists hold on to the idea that phenomenal concepts are recognitional, then they are unable to explain what it is that Mary acquires as she leaves her room and experiences shades of colour. This response to the KA then fails.

Of course, one way of avoiding the problem is just not to take phenomenal concepts as being recognitional. It was, after all, this way of understanding the nature of phenomenal concepts that led to the problem in the first place. But if phenomenal concepts are not recognitional, what could they be? Well, maybe they are demonstrative concepts. In the remainder of the paper, I consider this option, and show that it also leads to serious problems for the physicalists' response to the KA.

\section{Phenomenal concepts as demonstrative concepts}

John Perry (2001, p. 55-56) is among those who defend the view that recognitional concepts are demonstrative. In talking about the concept of pain, he writes:

As one has it [a pain], one attends to it, and thinks of it as "that sensation" (where "that" is intended to suggest the sort of thinking one does while attending to aspects of one's inner life). What more direct, more clear and distinct concept could one have of pain than one that involved attention to the very having of pain?

But of course we have a concept of pain when we are not in pain. A normal concept of pain, however, would be what I call demonstrative/recognitional; the concept has been formed by having pain, it includes a Humean memory of what it is like to have it, and these suffice to recognize when one is in pain.

So, according to Perry, we form concepts for our sensations while we attend to them. These concepts are in part demonstrative in nature, concepts 
of the form that sensation. But they also have a recognitional aspect to them, since we supposedly can keep information about the sensation in memory, and recognize it as it is experienced again.

We have seen that, at least regarding sensations involved in colour perception, we are typically not able to recognize them, not even for a short while after their initial presentation in experience. Given this, let us not suppose, with Perry, that phenomenal concepts are in part recognitional in nature. Let us suppose, for now, that phenomenal concepts are purely demonstrative.

Now, it has been supposed by many writing on demonstrative concepts that, in order for one to possess a demonstrative concept for a given $\mathrm{X}$, one must be able to attend to X. Perry explicitly mentions that we form phenomenal concepts for sensations while we attend to them. Regarding our forming of demonstrative concepts for things we perceive in the world, Gareth Evans writes (1982, p. 175/ Evans' italics): "The fundamental basis, then, of a demonstrative Idea of a perceptible thing is a capacity to attend selectively to a single thing over a period of time".

Evans seems to be right about this. Considering the possession of demonstrative concepts for observable things in the world, it seems clear that, if we are not able to attend to it, we cannot have a demonstrative concept for it. ${ }^{1}$ Consider, for instance, the following case. Sitting in his living room, Mark says to John, his friend, "That mosquito is so irritating". There are, however, plenty of mosquitoes in the room, and John asks "Which one?". If Mark were unable to say which one - or to point to a particular mosquito it seems clear that Mark's expression would not be referring to any mosquito in particular, and that he would not be having a thought about any mosquito in particular. In that case, it seems intuitive that Mark is not having a genuine demonstrative thought, a thought that actually refers demonstratively to something in particular. John, for instance, would certainly not take Mark as referring and thinking about any mosquito in particular. If Mark does not have a genuine demonstrative thought, he does not have a demonstrative concept for one mosquito in particular. If he did, he would be able to apply it in thought. And he does not have a demonstrative concept for a particular mosquito because he does not, and cannot, attend to a particular mosquito.

So, it seems to me that Evans is right in thinking that attending to a given observable thing in the world is a necessary condition for one to have

${ }^{1}$ For a detailed defense of this position, see Campbell (1997).

Rev. Filos., Aurora, Curitiba, v. 22, n. 30, p. 83-97, jan./jun. 2010 
a demonstrative concept for it. And the same applies to internal happenings, such as sensations. There can be no demonstrative thoughts or demonstrative concepts without attention. Thus, in order for one to have a genuine demonstrative thought about a given sensation, and a demonstrative concept, one must be able to attend to it.

Now I'm ready to state my argument. Going back to the case of colour perception and sensations generated by colour perception, what I will argue is that typically we cannot attend to these sensations, in which case we can have no demonstrative concepts for them.

Take my perceptual experience at this very moment. In front of me I see a notebook of a given shade of black, a picture filled with shades of red, leaves of different shades of green, and a number of other things. Now, I do not wish to deny that there are sensations attached to my perception of a given shade of black, of green or of red. But it seems clear to me that, in the typical case, these are not the kinds of sensations I can attend to. When I try to attend to the sensation I have when being presented with a given shade of red in perception, I only find myself attending to the shade itself. When looking at the green leaves in front of me, I cannot attend to any sensation in particular, generated by my experience of a given shade of green. Again, I can only attend to the shade itself.

Now, it is certainly the case that, on certain occasions, in being shown certain shades of colour we have sensations that are particularly vivid. Jane may find the shade of blood incredibly beautiful, so that when she is presented with the shade, she has those vivid sensations associated with experiencing beauty. Julie may be disgusted by blood, so that, when she is presented with the shade blood-red, she has vivid and unpleasant sensations. In such cases, given the vividness of the sensations, it seems clear that we can attend to them, and form demonstrative concepts. But these are exceptions. Everyday colour perception is not like that. In being presented with most shades in everyday life, there is no sensation associated with the experiences that is so vivid that we can attend to it.

Since attention is required for possession of demonstrative concepts, then we cannot form demonstrative concepts for most sensations associated with colour experiences. Which means that, if phenomenal concepts are demonstrative and demonstrative only, then we do not possess phenomenal concepts for most sensations associated with colour experiences.

What should we say of Mary? Well, it seems that we should say that Mary does not possess demonstrative concepts for most of the sensations 
associated with her colour experiences. And, again, taking phenomenal concepts to be demonstrative, she does not possess phenomenal concepts for most sensations associated with her colour experiences.

One could say, however, that, since Mary is being presented with colour for the first time in experience, her sensations are particularly vivid, so that she can attend to them, thus being able to form demonstrative concepts. Well, maybe her sensations are indeed particularly vivid. However, even if she has vivid sensations, these are likely to be in a way similar to the mosquitoes in the room: too many and too briefly perceived (felt) to be the object of Mary's attention. That is, in perceiving a shade of red for the first time, Mary may be bombarded by sensations of all sorts at the same time, so that she cannot attend to any particular sensation. Of course, this is all phenomenological speculation, since we do not know what it is like to be Mary in leaving her room, but there seems to be little reason to suppose that, in being presented with her first shades of colour, Mary's sensations are vivid and discernible enough so that she can attend to them, and form demonstrative concepts.

So, it seems that, if physicalists want to explain what it is that Mary acquires in leaving the room in terms of her acquiring phenomenal concepts, they cannot take theses concepts as being demonstrative. Because it seems at best very unlikely that Mary acquires demonstrative concepts for the sensations she has when presented with colour shades. As we have seen, physicalists should also not take phenomenal concepts to be recognitional, because Mary does not acquire recognitional concepts for most sensations associated with experiences of colour shades in leaving her room. If physicalists want to sustain that Mary acquires phenomenal concepts in leaving her room, then the challenge they face is that of explaining the nature of such concepts, not supposing them to be recognitional or demonstrative, and showing that their nature is compatible with Mary's acquiring these concepts as she has her first sensations generated by colour experiences.

\section{Conclusion}

A number of physicalists have responded to Frank Jackson's KA by supposing that Mary, in leaving her room, acquires phenomenal concepts for the sensations she has when presented with colour shades in perception. The sensations themselves would be physical events, and Mary would only be 
acquiring concepts under which can subsume these events. Of course, in order to evaluate this hypothesis, we have to know what the nature of phenomenal concepts is. In this paper, I have considered two options, one according to which phenomenal concepts are recognitional, and the other according to which phenomenal concepts are demonstrative. We have seen that, in either case, it does not seem to be true that, in leaving her room, Mary acquires phenomenal concepts for the sensations attached to most of her experiences of shades of colour. So, if physicalists want to stick to this line of response to the $\mathrm{KA}$, they have to offer some other account of the nature of phenomenal concepts, and show that, given this account, it is plausible to suppose that Mary acquires such concepts in leaving her room and being presented with shades of colour in experience.

None of this means, of course, that physicalism is false. It only means that one cannot respond to the KA argument by supposing that Mary acquires phenomenal concepts in leaving her room and, at the same time, supposing that these concepts are either recognitional or demonstrative.

\section{References}

BURNHAM, R. W.; CLARK, J. R. A test of hue memory. The Journal of Applied Psychology, v. 39, n. 3, p. 164-172, 1955.

CAMPBELL, J. Sense, reference and selective attention. Proceedings of the Aristotelian Society, v. 71, p. 55-74, 1997.

CARRUTHERS, P. Phenomenal consciousness: a naturalistic theory. Cambridge, MA: Cambridge University Press, 2000.

EPPS, H. H.; KAYA, N. Color matching from memory. In: INTERIM MEETING OF THE INTERNATIONAL COLOR ASSOCIATION, 2004, Porto Alegre. Proceedings... Porto Alegre: [s. n.], 2004. p. 18-21. Disponível em: <www.fadu.uba. ar/sitios/sicyt/color/aic2004/018-021.pdf>. Acesso em: 20 nov. 2009.

EVANS, G. The varieties of reference. Oxford: Clarendon Press, 1982.

JACKSON, F. Epiphenomenal qualia. Philosophical Quaterly, v. 32, n. 127, p. 127 $136,1982$.

LOAR, B. Phenomenal states. Philosophical Perspectives, v. 4, p. 81-108, 1990.

Rev. Filos., Aurora, Curitiba, v. 22, n. 30, p. 83-97, jan./jun. 2010 
PERRY, J. Knowledge, possibility and consciousness. Cambridge, MA: MIT Press, 2001.

TYE, M. Color, consciousness and content. Cambridge, MA: MIT Press, 2000.

Received: 03/26/2010

Recebido: 26/03/2010

Approved: 05/05/2010 Aprovado: 05/05/2010 